\title{
Review \\ Degradation of Hair Surface: Importance of 18-MEA and Epicuticle
}

\author{
Shinichi Tokunaga ${ }^{1, *}$, Hiroto Tanamachi ${ }^{1}$ and Kazutaka Ishikawa ${ }^{2}$ \\ 1 R\&D—Hair Care Products Research, Kao Corporation, Tokyo 131-8501, Japan; tanamachi.hiroto@kao.com \\ 2 R\&D-Analytical Science Research, Kao Corporation, Wakayama 640-8580, Japan; \\ ishikawa.kazutaka@kao.com \\ * Correspondence: tokunaga.shinichi@kao.com
}

Received: 25 March 2019; Accepted: 5 May 2019; Published: 9 May 2019

\begin{abstract}
In this paper, surface degradation of hair is reviewed. Surface properties such as hydrophobicity and surface friction change as surface structures of hair fiber, that is, 18-methyleicosanoic acid (18-MEA) and epicuticle, degrade. Comparison of contact angle and amount of 18-MEA from root to tip of the sampled hair fibers clarified the contribution of not only 18-MEA but also epicuticle to surface properties. It was found that chemical treatment by itself, such as bleaching, is not enough to cause complete loss of hydrophobic nature even after 18-MEA is removed. Additional weathering processes, such as repeatedly shampooing, are required. A technology for the deposition of a persistent hydrophobicity to bleached and weathered hair surfaces using 18-MEA is presented. Combination of 18-MEA with specific cationic surfactants (Stearoxypropyldimethylamine: SPDA) made the bleached and weathered hair surface hydrophobic, and its hydrophobicity was maintained even after shampooing. Characterization of adsorbed layers of 18-MEA/SPDA on a mica surface, as a possible hydrophilic surface model, was performed using atomic force microscopy (AFM) and angle-resolved X-ray photoelectron spectroscopy (AR-XPS). The effects of the anteiso-branch moiety of 18-MEA to create a persistent hydrophobicity with 18-MEA/SPDA were investigated using controlled AFM. It was revealed that the anteiso-branch moiety of 18-MEA in the 18-MEA/SPDA system produces a persistent hydrophobicity by providing higher fluidity to the upper region of the 18-MEA/SPDA layer. The contribution to hair beauty and sensory feeling as one of the practical functions of the hair surface is described in this paper. The hydrophobic nature of the hair surface reduces surface friction in a wet state, which reduces hair disorder alignment. It is also revealed that the moisturized or dried out feeling strongly depends on the hair shape (meandering and diameter) which depends on hair surface properties in a wet environment.
\end{abstract}

Keywords: 18-MEA; epicuticle; hair surface

\section{Introduction}

Healthy and beautiful hair is desirable for many women with hair damaged by chemical treatments, heat styling and environmental factors. Various hair care products have been developed for improving hair beauty. Detailed knowledge of the surface structure and properties of hair is essential for developing unique hair care technologies. The cuticle is located on the outside of the hair fibers, protecting the cortex. It has been suggested that the outermost surface of the cuticle cells has been covered by a monolayer of covalently bound fatty acids, a major component of which is 18-methyleicosanoic acid (18-MEA) [1-4].

18-MEA is an unusual branched-chain fatty acid. It is covalently bound, possibly via thioester or ester linkage, to the cuticle surface of hair fibers [5-8]. It is known that 18-MEA creates a hydrophobic surface and acts as a boundary lubricant to reduce friction resistance between hair fibers [9-14]. 
18-MEA is easily removed by alkaline treatments, such as hair coloring or permanent waving, and the surface becomes hydrophilic and friction increases $[13,14]$. The loss of 18-MEA is considered one of the reasons for the friction increase on the surface of the cuticle. It may have an influence on the sensory perception of hair, such as the dried out feeling and being hard to comb/ run fingers through [11].

The purpose of this review article is to describe these points, mainly focusing on the degradation and recovery of the hair surface.

1. To better understand the relationship between surface properties and the amount of 18-MEA.

2. To clarify contribution of epicuticle to the surface properties such as hydrophobicity.

3. To regenerate the hydrophobic layer onto hair surface using 18-MEA and clarify the role of the anteiso-branch at the terminal of alkyl chain of 18-MEA.

4. To clarify the contribution of 18-MEA to practical aspects such as hair appearance and sensory perception.

\section{Materials and Methods}

\subsection{Materials}

\subsubsection{Hair Fibers}

Sampled hair fibers for study of the relationship between surface properties and the amount of 18-MEA were prepared as follows. Hair fibers were kindly provided by 48 Japanese females cut at the root end. Each fiber was cut at $5 \mathrm{~cm}$ intervals from the root end to the tip after washing. Chinese hair, Blonde hair and Brunette hair were also kindly provided by female volunteers. The number of volunteers were 19 for Chinese hair, 19 for Blonde hair, and 11 for Brunette hair. These hair fibers were treated by the same procedure as Japanese hair.

Untreated hair, bleached hair (B4 hair), and bleached and weathered hair (B4W hair) for study of the contribution of epicuticle to surface properties were prepared as follows. Hair fibers were kindly provided by Japanese females who had no experience of chemical hair treatments. Hair fibers were cut from the root end. B4 hair was prepared by four times treatment with bleaching lotion for 20 minutes. Formulation of bleaching lotion is listed in Table 1. B4W hair was prepared by 4 times bleaching treatment coupled with model weathering 360 times. 90 times model weathering was carried out between every bleaching. The procedure is described in the following article [15]. The shampoo formulation is listed in Table 2.

Table 1. Formulation of bleaching lotion ( $\mathrm{pH} 9.0)$.

\begin{tabular}{cc}
\hline $35 \%$ Hydrogen peroxide & $10 \mathrm{wt} \%$ \\
$28 \%$ Ammonia Water & $2.7 \mathrm{wt} \%$ \\
Ammonium Bicarbonate & $5.6 \mathrm{wt} \%$ \\
Cetyl trimethylammmonium chloride & $2.0 \mathrm{wt} \%$ \\
EDTA/2Na & $0.5 \mathrm{wt} \%$ \\
Water & Balance \\
\hline
\end{tabular}

Table 2. Formulation of Shampoo (pH 7).

\begin{tabular}{cc}
\hline Sodium polyoxyethylene lauryl ether sulfate(2.5 E.O) & $15 \mathrm{wt} \%$ \\
$N, N$-bis(2-hydroxyethyl)dodecanamide & $2 \mathrm{wt} \%$ \\
phosphoric acid & Adjust to $\mathrm{pH} 7$ \\
Water & Balance \\
\hline
\end{tabular}

Untreated hair and bleached and weathered hair for study of regeneration of the hydrophobic layer onto hair surface using 18-MEA were prepared as follows. Hair fibers were kindly provided by a Japanese female. The fibers were cut at approximately $20 \mathrm{~cm}$ from the root end. The hair had 
never been treated with any chemical agents. Bleached and weathered hair was prepared as the same procedure of B4W hair.

Preparation of 18-MEA removed hair for study of contribution of 18-MEA to hair appearance was as follows. Hair fibers kindly provided by a Japanese female were treated with a solution of $0.1 \mathrm{M}$ potassium t-butoxide in t-butanol, for $5 \mathrm{~min}$ at room temperature, and at a liquor:fiber ratio of 10:1. The alkali was then removed by rinsing the hair with t-butanol $(2 \times)$, ethanol and, finally, by washing in water.

Hair fibers for study of hair shape and sensory perception were prepared as follows. Hair fibers were kindly provided by 19 Japanese females. The fibers were cut at a distance of approximately $15 \mathrm{~cm}$ from the root on the back of their head. 19 hair swatches (20-25 cm in length, 15-20 g in weight), which had experienced a variety of damage. The hair swatches were washed with a plain shampoo which formulation is written in Table 1. The wet hair swatches were then towel dried, followed by air drying without tension.

\subsubsection{Mica as a Model for the Hydrophilic Surface}

A fresh mica sheet was used as a model for the hydrophilic surface of bleached and weathered hair. Mica sheets of approximately $10 \mathrm{~mm} \times 10 \mathrm{~mm} \times 0.1 \mathrm{~mm}$ were cleaved on both sides immediately prior to use. They were then immersed in a conditioner solution for 1 minute at $40^{\circ} \mathrm{C}$. The mica sheets were then rinsed under running distilled water for 30 seconds and naturally dried.

Procedure of conditioner treatment to mica was as follows. Mica sheets were immersed in a conditioner solution for 1 minute at $40^{\circ} \mathrm{C}$. The mica sheets were then rinsed under running distilled water for 30 seconds and naturally dried.

\subsubsection{Chemicals}

18-methyleicosanic acid (18-MEA) and stearoxypropyldimethylamine (SPDA) were obtained by chemical synthesis [16,17]. Other chemicals were commercially available.

\subsection{Methods}

\subsubsection{Amount of 18-MEA and Sulfonate Group on the Surface of Hair}

Semi-quantitative analysis of 18-MEA and sulfonate group on the surface of the hair fiber were measured by a Time-of-Flight Secondary Ion Mass Spectrometry (TOF-SIMS) IV instrument (ION-TOF $\mathrm{GmbH}$, Münster, Germany) using $25-\mathrm{keV} \mathrm{Bi}^{32+}$ primary ions in high-current bunched mode. The analysis area of $50 \mu \mathrm{m} \times 50 \mu \mathrm{m}$ was randomly rastered by primary ions and was charge-compensated by low-energy electron flooding. The amount of 18-MEA and sulfonate group were expressed as the relative ion yield of 18-MEA versus the $\mathrm{CN}$ ion yield, which was derived from hair proteins [18]. In this study, the $\mathrm{CN}$ ion was used for normalization since the matrix of hair surface is keratinous protein and the $\mathrm{CN}$ ion was strongly detected in the TOF-SIMS measurement of hair samples.

Atomic concentration of S(IV), which is proportional to the amount of sulfonate group [19], was measured by X-ray photoelectron spectroscopy measurements (XPS) using a PHI Quantera SXM instrument (Ulvac PHI, Kanagawa, Japan) equipped with a monochromatized and focused $\mathrm{Al} \mathrm{K \alpha}$ X-ray beam. All XPS measurements were performed using a focused X-ray source (diameter $100 \mu \mathrm{m}$; power $25 \mathrm{~W}$ ) with the photoelectron pass energy of $112 \mathrm{eV}$. Charge compensation of the samples was accomplished using a dual beam charge compensation system that utilizes both an electron flood source and a low energy argon ion sputter gun. Binding energy values were corrected relative to the C1s peak at $284.8 \mathrm{eV}$.

\subsubsection{Measurement of Surface Properties of Hair.}

Dynamic contact angles (advancing contact angle and receding contact angle) were measured by the Wilhelmy method [20,21] using a K100MK2 tensiometer (Krüss GmbH, Hamburg, Germany). 
Single hair fibers were scanned over $3 \mathrm{~mm}$ at a velocity of $2 \mathrm{~mm} / \mathrm{min}$ for the advancing mode. Dynamic contact angles were calculated from

$$
\mathrm{F}=\pi \mathrm{d} \gamma \cos \theta
$$

where $\mathrm{F}$ is the wetting force, $\mathrm{d}$ is the diameter of hair, $\gamma$ is the surface tension of water and $\theta$ is the contact angle of the liquid versus fiber surface. The hair fiber diameter was measured on the transverse section of each fiber with a rotating fiber diameter measurement system equipped with a laser (Kato Tech Co., Kyoto, Japan) at $20^{\circ} \mathrm{C}$ and the relative humidity (RH) of $65 \%$. The wetting force measurements were also performed at $20^{\circ} \mathrm{C}, 65 \% \mathrm{RH}$.

Elastic modulus of surface of hair fibers in wet environment were measured by atomic force microscopy (AFM) nanoindentation using Multimode NanoScope V equipped with a fluid cell (Bruker, Santa Barbra, CA, USA). Force-displacement curves were collected by force-volume mode $(16 \times 16$ points within $3 \mu \mathrm{m} \times 3 \mu \mathrm{m}$ area) using silicone probes (NCHV). The Young's modulus of the all points was determined by curve fitting based on Hertz model.

Frictional properties of the surface of hair in the wet environment were measured using a Nanoscope III Dimension 3000 (Veeco Instruments, Santa Barbra, CA, USA). Friction force microscopy (FFM) data were acquired using unmodified silicon nitride (Si-N) cantilevers (spring constant of $0.12 \mathrm{Nm}^{-1}$ ). After engagement of the tip with the cuticle surface, the tip was scanned parallel to the longitudinal axis of the fiber. To characterize frictional properties, $2 \mu \mathrm{m} \times 2 \mu \mathrm{m}$ scans of the cuticle faces (without edges) were performed.

Frictional properties of the surface of hair in the dry environment were measured using a KES-SE friction tester (Kato Tech Co., Kyoto, Japan). The hair strands were mounted on a glass plate in such a way that all strands of hair were separated and parallel to each other at $5 \mathrm{~mm}$ intervals. The test was conducted at a temperature of $20^{\circ} \mathrm{C}$ and a relative humidity of $65 \%$.

Heat transfer characteristic $\left(\mathrm{q}_{\max }\right)$ of hair was measured using a KEF-F7 Finger-robot Thermo Labo (Kato Tech Co., Kyoto, Japan) [22]. A sensor covered with silicon rubber, which has properties similar to those of human skin, was heated to $36^{\circ} \mathrm{C}$. By bringing the sensor into contact with a hair tress, heat was transferred from the temperature sensor to the hair tress. Based on the temperature changes, heat transfer speed " $q$ " was measured, and then the peak value " $\mathrm{q}_{\max }$ " was calculated.

\subsubsection{Measurement of Surface Properties of Adsorbed Layer on Mica}

AFM images of the adsorbed layer on the mica surfaces were obtained using a Nanoscope IIIa Multi Mode AFM (Veeco Instruments, Santa Barbara, CA, USA) with an E-Scanner. Tapping mode imaging was used to obtain topographic images of the adsorbed membrane layers. To ensure that imaging the membrane caused no damage, the tapping force was set at the lowest possible level. The nominal spring constants of cantilevers are reported by the manufacturer to be $20-100 \mathrm{~N} / \mathrm{m}$. All images presented in this work were obtained reproducibly over at least three spots on the sample surfaces. The images were acquired with a scan rate of either 0.5 or $1.0 \mathrm{~Hz}$ and were flattened with a first-order polynomial prior to analysis.

The mechanical properties of the adsorbed membrane were analyzed using the AFM scratching method [23-26], using a Nanoscope IIIa Multi Mode AFM. Scratching of the adsorbed membrane was performed in contact mode at a constant force and a micro fabricated tip made of silicon nitride (Si-N) and a cantilever, having a spring constant $0.38 \mathrm{~N} / \mathrm{m}$, was used. First, an image (typically, $5 \mu \mathrm{m} \times 5 \mu \mathrm{m}$ ) of the adsorbed membrane was acquired, then, a smaller area (typically $1 \mu \mathrm{m} \times 1 \mu \mathrm{m}$ ) was scanned while loading the tip hard onto the surface. Following this, the scanning was repeated over the larger area. This method is hereafter called "scratching". Thus, if the adsorbed layer was strongly bound to the surface, it was harder to remove.

Measurements of the thicknesses of the adsorbed layers on the mica surfaces were obtained using a NanoScope V multi mode AFM (Veeco Instruments, Santa Barbara, CA, USA), equipped with an environment control cell, and the substrate temperature was controlled using a heating stage, which has been modified to be programmable. Firstly, the membrane thickness was measured at room 
temperature, then the temperature of the sample stage decreased at a rate of $1^{\circ} \mathrm{C} / \mathrm{min}$ to a temperature $\left(25^{\circ} \mathrm{C}, 15^{\circ} \mathrm{C}, 5{ }^{\circ} \mathrm{C}, 0{ }^{\circ} \mathrm{C},-5^{\circ} \mathrm{C}\right.$ and $\left.-10^{\circ} \mathrm{C}\right)$, where it was maintained for at least an hour.

Molecular orientation of the 18-MEA/SPDA layer was determined by angle-resolved X-ray photoelectron spectroscopy (ARXPS) [15] which is a nondestructive method to obtain elemental and chemical-state information as a function of depth. ARXPS data was obtained using a Quantera SXM spectrometer (ULVAC PHI, Kanagawa, Japan) with a monochromatized Al K $\alpha$ X-ray source at $15 \mathrm{kV}$ and $25 \mathrm{~W}$. Survey spectra were recorded at a takeoff angle of $45^{\circ}$ and pass energy of $280 \mathrm{eV}$ with a cylindrical-mirror analyzer. Angle resolved spectra were recorded at five takeoff angles, 70, 45, 25, 15, 10 degrees in a high energy resolution mode with pass energy of $112 \mathrm{eV}$.

\section{Results}

\subsection{The Relationship between Surface Properties and the Amount of 18-MEA}

The relationship between dynamic contact angles (advancing and receding) and the semi-quantitative amount of 18-MEA on the surface of hair measured by TOF-SIMS was investigated [18]. In addition to Japanese hair, the same measurements were carried out for Chinese hair, Blonde hair and Brunette hair. Figure 1 illustrates the relationship between dynamic contact angles (advancing and receding) and semi-quantitative amount of 18-MEA on the surface of hair measured by TOF-SIMS. Blue squares indicate the advancing contact angle and red triangles indicate the receding contact angle.

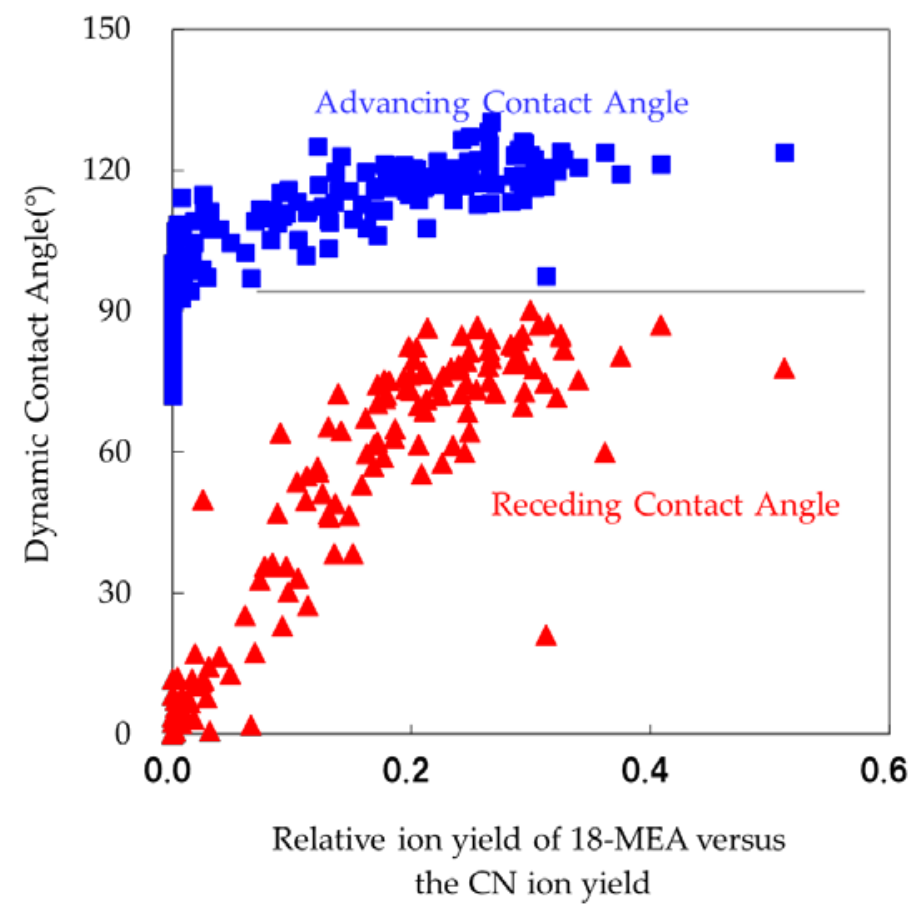

Figure 1. Relationship between dynamic contact angles (advancing and receding) and the semi-quantitative amount of 18-methyleicosanoic acid (18-MEA) on the surface of Japanese female hair measured by TOF-SIMS.

Both of the contact angles decreased as the amount of 18-MEA decreased. For Chinese, Blonde and Brunette hair the same tendency has been observed in relationship between dynamic contact angle and the amount of 18-MEA (Figure 2). 


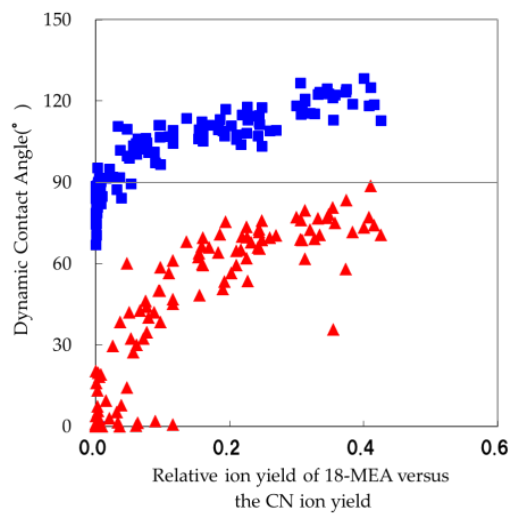

(a)

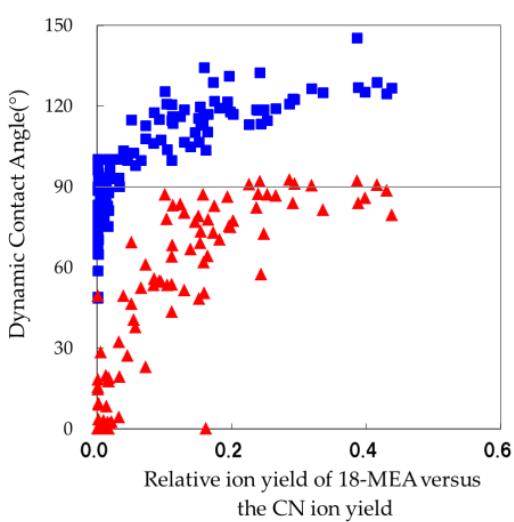

(b)

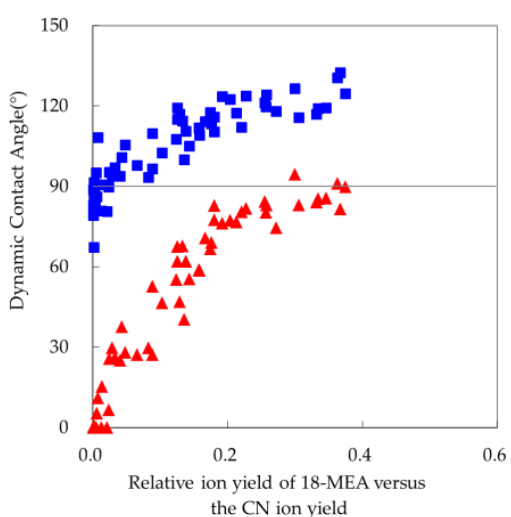

(c)

Figure 2. Relationship between dynamic contact angles (advancing and receding) and the semi-quantitative amount of 18-MEA on the outermost surface of (a) Chinese, (b) Blonde, and (c) Brunette female hair measured by TOF-SIMS. Same procedure as Japanese hair was adapted to analyze these hair fibers.

\subsection{Contribution of Epicuticle to the Hair Surface Properties}

The dynamic contact angles, amount of 18-MEA and sulfonate group (-SO $\left.{ }^{3-}\right)$ were measured for untreated hair, bleached hair (B4 hair), and bleached and weathered hair (B4W hair). The results are shown in Table 3. B4 hair has lost 18-MEA but keeps hydrophobicity. On the other hand, B4W hair has lost both 18-MEA and hydrophobicity. B4 hair had the highest amount of sulfonate groups. Surprisingly, although B4 hair samples have a higher amount of sulfonate groups compared to B4W hair samples it showed stronger hydrophobicity than B4W hair samples.

Table 3. Comparison of untreated hair, bleached hair (B4 hair) and bleached and weathered hair (B4W hair).

\begin{tabular}{ccccc}
\hline $\begin{array}{c}\text { Amount of 18-MEA, Sulfonate Group } \\
\text { and Contact Angles }\end{array}$ & $\begin{array}{c}\text { Untreated Hair } \\
\text { (Root Part) }\end{array}$ & B4 Hair & B4W Hair \\
\hline \multicolumn{2}{c}{ Amount of 18-MEA ${ }^{1}$} & $2.89\left(\times 10^{-1}\right)$ & N.D & N.D \\
\hline $\begin{array}{c}\text { Amount of } \\
\text { sulfonate group }\end{array}$ & $\begin{array}{c}\text { Measured by } \\
\text { TOF-SIMS }\end{array}$ & $6.70\left(\times 10^{-1}\right)$ & 1.53 & $6.10\left(\times 10^{-1}\right)$ \\
\hline \multirow{2}{*}{ Measured by XPS } & $0.12 \%$ & $0.85 \%$ & $0.61 \%$ \\
\hline
\end{tabular}

${ }_{1}^{1}$ Semi-quantitative amount of 18-MEA measured by TOF-SIMS, ${ }^{2}$ Semi-quantitative amount of Sulfonate group
measured by TOF-SIMS, ${ }^{3}$ Atomic concentration of S(IV) measured by X-ray photoelectron spectroscopy (XPS).

The elastic modulus of the epicuticle in a wet environment has been measured by AFM. The results are shown in Figure 3. Elastic modulus of B4 hair is almost same as that of untreated hair. B4W hair is around $80 \%$ of that of untreated hair. 


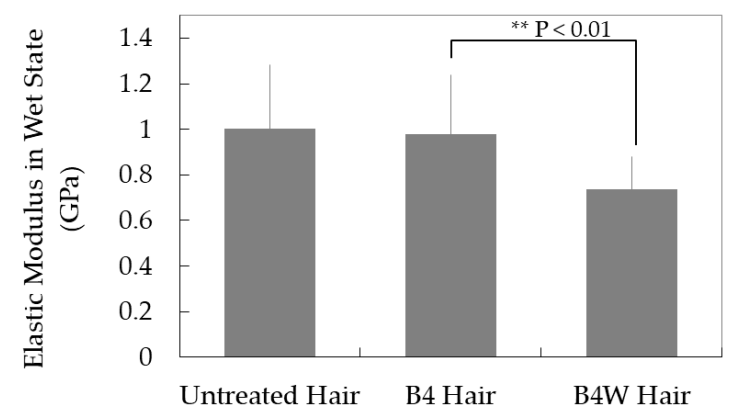

Figure 3. Elastic modulus measured by atomic force microscopy (AFM) nanoindentation in wet environment. Five hair fibers for untreated hair, B4 hair, and B4W hair respectively were measured.

\subsection{Regeneration of Hydrophobic Layer onto Hair Surface Using 18-MEA}

Regeneration of the hydrophobic layer onto the hair surface using 18-MEA has been studied [15]. Bleached and weathered hair was treated with 18-MEA and long-chain tertiary amine or quaternary cationic surfactant salts containing conditioners and shampooed (formulation of conditioners and shampoo is written in Tables 2 and 4; in Table 4, lactic acid has been used to neutralize dimethylaminopropylstearamide (DAPS) or SPDA because they are tertiary amines). Results are shown in Figure 4. Surface properties such as contact angle and friction were recovered to the level of healthy hair by application of conditioner containing 18-MEA/SPDA.

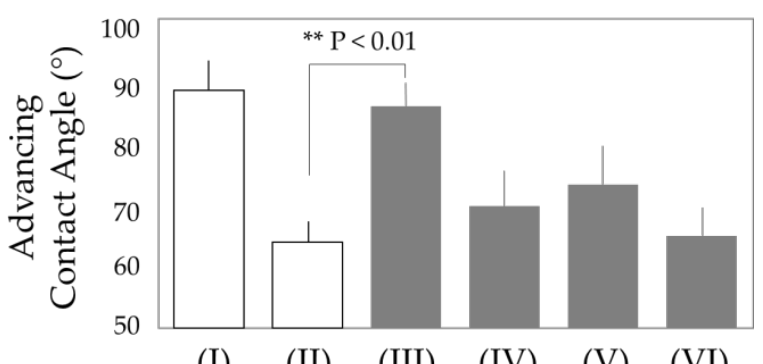

(I)

(II)
(IV)

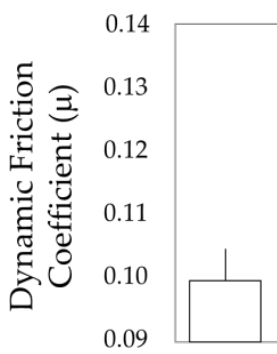

(I)

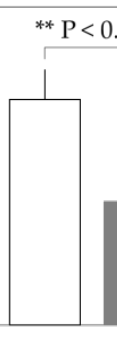

(II)

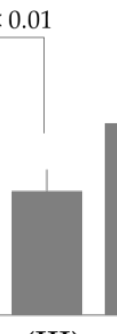

(III) (IV)

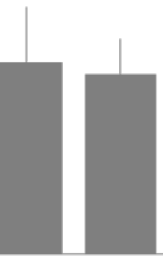

(V)

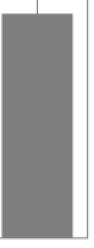

(VI)

(a)

(b)

Figure 4. (a) Advancing contact angle of each hair samples ( $\mathrm{N}=7$ for each). (I) Untreated Hair. (II) Bleached and weathered hair. (III) Bleached and weathered hair treated with 18-MEA/SPDA containing conditioner. (IV) Bleached and weathered hair treated with conditioner containing 18-MEA/DAPS (Dimethylaminopropylstearamide). (V) Bleached and weathered hair treated with conditioner containing 18-MEA/STAC (Stearyltrimethylammonium Chrolide). (VI) Bleached and weathered hair treated with control conditioner. (b) Dynamic friction coefficient of each hair samples ( $\mathrm{N}=5$ for each).

Table 4. Formulations of the conditioners (wt \%).

\begin{tabular}{ccccc}
\hline Ingredient & Conditioner 1 & Conditioner 2 & Conditioner 3 & Conditioner 4 (Control) \\
\hline Stearoxypropyldimethylamine (SPDA) & 2 & - & - & 2 \\
Dimethylaminopropylstearamide (DAPS) & - & 2 & - & - \\
Stearyltrimethylammonium chloride & - & - & 2 & - \\
(STAC) & 0.5 & 0.5 & 0.5 & 0.5 \\
Benzyl alcohol & 3 & 3 & 3 & - \\
Stearyl alcohol & 1 & 1 & 1 & 0.6 \\
18-MEA & 0.3 & 0.3 & - & \\
Lactic Acid & & & Balance & \\
Water & &
\end{tabular}


AFM height images of the adsorption layer on mica after treated with conditioners are shown in Figure 5. In this figure, dark areas are mica without sorbed compounds, and bright areas indicate the existence of a sorbed layer from conditioner. Adsorption layer made by salt of 18-MEA and SPDA (18-MEA/SPDA) covered mica uniformly. Regarding the thickness of the18-MEA/SPDA layer, it was estimated to be about $1 \mathrm{~nm}$.

Adsorption layer of 18-MEA/SPDA showed wear resistance. Figure 6 shows AFM height image after scratching test using a rastering a tip with constant force. The white squares indicate where $1000 \mathrm{~nm} \times 1000 \mathrm{~nm}$ scratching tests have been done. In the image of adsorbed film treated by (b) 18-MEA/DAPS or (c) 18-MEA/stearyltrimethylammonium chloride (STAC), a square groove was observed. On the other hand, treatment by (a) 18-MEA/SPDA showed no such groove. These results indicate that the 18-MEA/SPDA conditioner adsorbed homogeneously on the mica surface and had a high wear resistance.

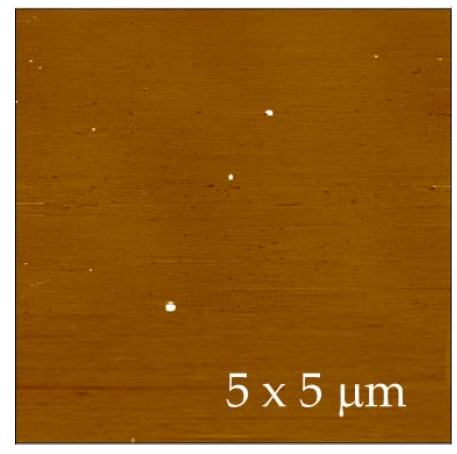

(a)

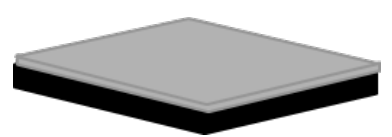

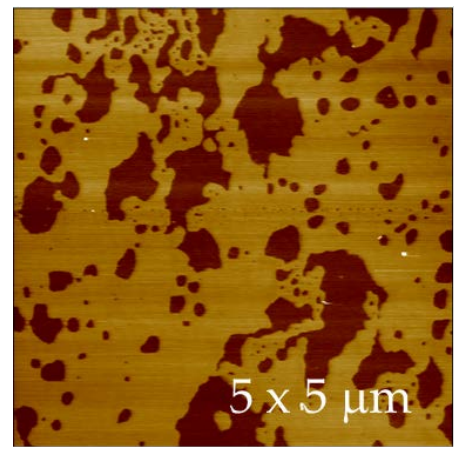

(b)

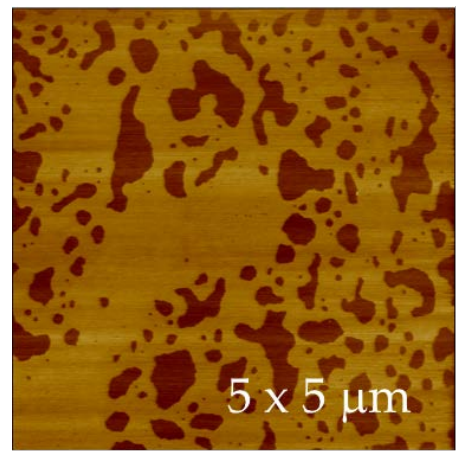

(c)

Figure 5. AFM height image of adsoeped layer on mica surface. Dark areas are mica without sorption. Bright areas are sorped layer from conditioner. (a) 18-MEA/SPDA. (b) 18-MEA/DAPS. (c) 18-MEA/STAC.

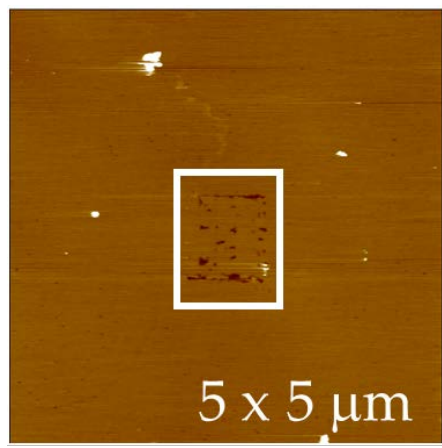

(a)

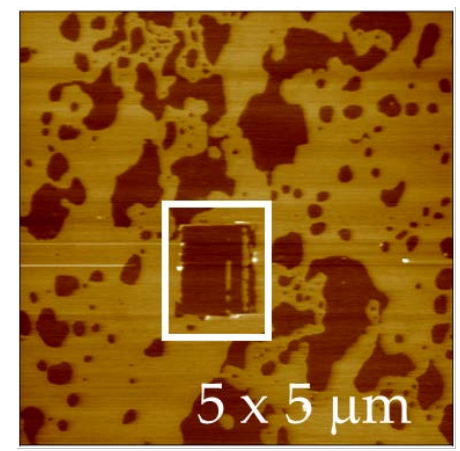

(b)

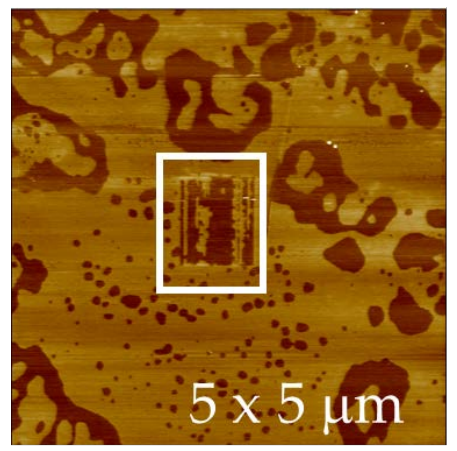

(c)

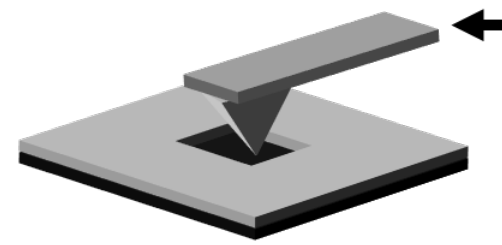

AFM probe tip

Scratch Surface with constant Force $(=10 \mathrm{nN})$

Figure 6. AFM height image of adsoeped layer on mica surface. Dark areas are mica without sorption. Bright areas are sorped layer from conditioner. The white squares indicate where $1000 \mathrm{~nm} \times 1000 \mathrm{~nm}$ scratching test were done. (a) 18-MEA/SPDA. (b) 18-MEA/DAPS. (c) 18-MEA/STAC. 
Figure 7 shows the temperature dependency of the adsorption layer thickness composed of 18-MEA/SPDA and n-heneicosanoic acid (n-HEA)/SPDA. The layer thickness of 18-MEA/SPDA drastically increased at a temperature around $0 \sim 10^{\circ} \mathrm{C}$. On the other hand, the layer thickness of n-HEA /SPDA is more stable from the temperature range of $25^{\circ} \mathrm{C}$ to $-10^{\circ} \mathrm{C}$.

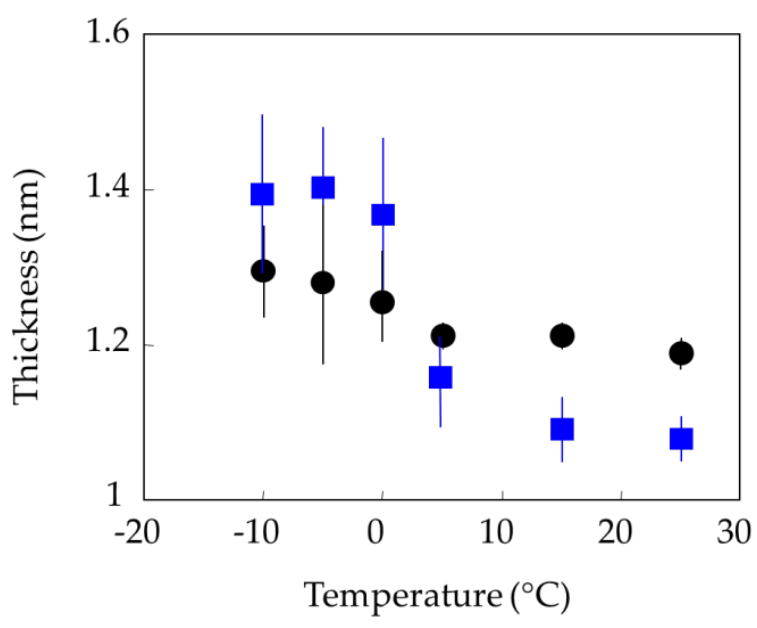

(a)
- At room temperature

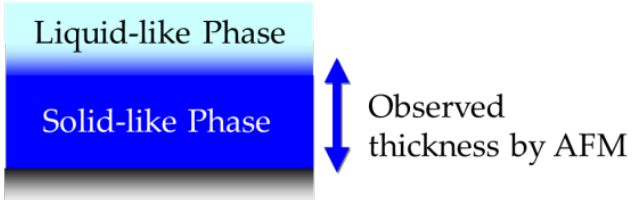

At cold temperature (Below $0^{\circ} \mathrm{C}$ )

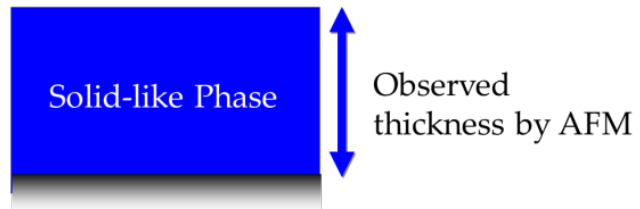

(b)

Figure 7. (a) Temperature dependency of AFM height image of adsorped layer on mica surface for 18-MEA/SPDA ( $\mathbf{\square})$ and n-HEA/SPDA $(\bullet)$. The whiskers represent the standard deviations $(\mathrm{n}=5)$.

(b) Schematic image of observed thickness at room temperature and at cold temperature (below $0{ }^{\circ} \mathrm{C}$ ).

Molecular orientation of 18-MEA/SPDA layer was determined by angle-resolved X-ray photoelectron spectroscopy (ARXPS) [15]. The results are shown Figure 8. Both the peak area ratio of $\mathrm{N}$ (Nitrogen)/C(Carbon) from SPDA and COO(carboxyl)/C(Carbon) from 18-MEA increased with the measurement depth.

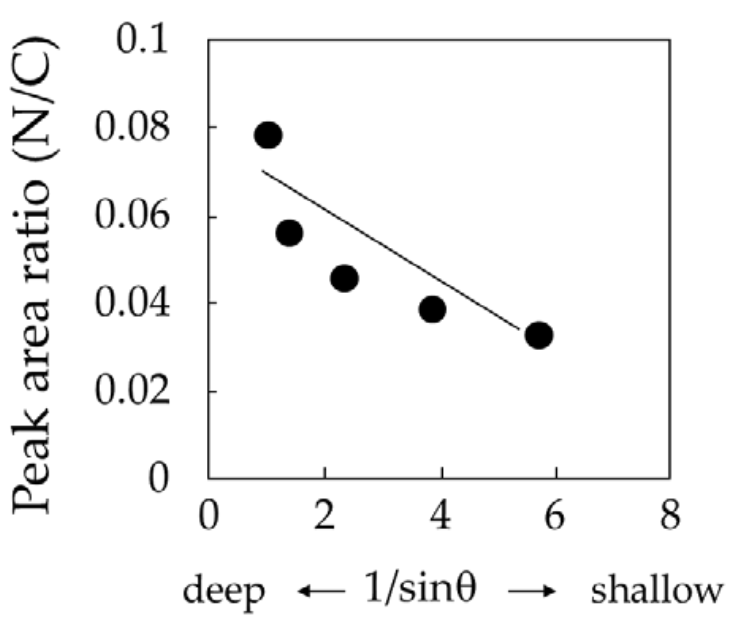

(a)

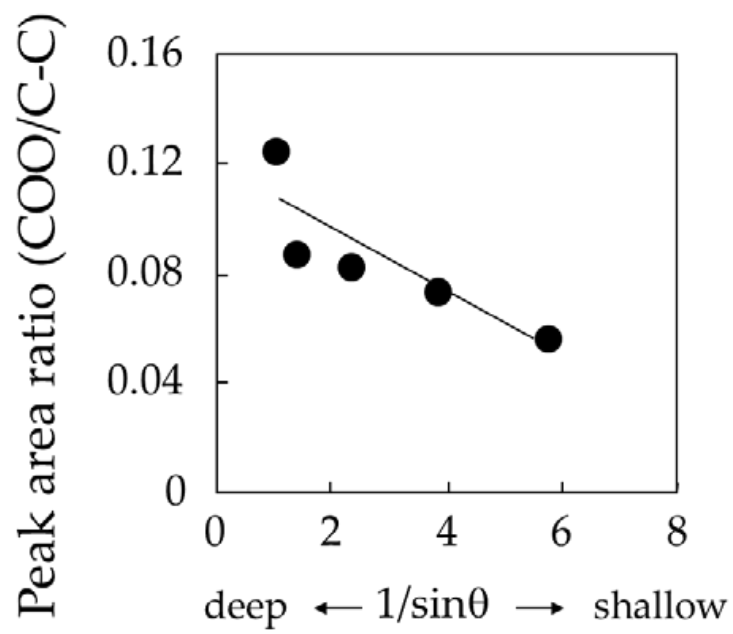

(b)

Figure 8. Molecular orientation analysis of 18-MEA/SPDA membrane by angle resolved X-ray photoelectron spectroscopy (ARXPS). (a) Angle dependence of N(Nitrogen)/C(Carbon) concentration derived from SPDA. (b) Angle dependence of $\mathrm{COO}($ carboxyl)/C(Carbon) concentration derived from 18-MEA. 


\subsection{Influences of 18-MEA on Hair Appearance and Sensory Perception}

The influence of the removal of 18-MEA especially in a wet state has been studied [18]. Summary of structural and physical properties of hair are listed in Tables 5 and 6. Removal of 18-MEA and decrease in contact angle were observed. Friction forces measured using the FFM technique [11] are shown in Figure 9 Surface friction increased after removal of 18-MEA in a wet state. To the contrary there was almost no change in surface feature and physical properties inside hair fibers.

Table 5. Structural and physical properties of hair before and after removing 18-MEA $(\mathrm{N}=7)$.

\begin{tabular}{|c|c|c|}
\hline $\begin{array}{l}\text { Surface Feature and } \\
\text { Physical Properties }\end{array}$ & Untreated Hair & Hair after Removal of 18-MEA \\
\hline \multicolumn{3}{|l|}{ SEM image } \\
\hline $\begin{array}{c}\text { Diametric swelling ratio } \\
\text { in water }(\%)\end{array}$ & $1.08 \pm 0.02$ & $1.08 \pm 0.15$ \\
\hline $\begin{array}{l}\text { Elastic modulus in water } \\
\qquad\left(\times 10^{10} \text { dyns } / \mathrm{cm}^{2}\right)\end{array}$ & $1.77 \pm 0.26$ & $1.68 \pm 0.53$ \\
\hline $\begin{array}{c}\text { Breaking stress in water } \\
\left(\times 10^{9} \mathrm{dyns} / \mathrm{cm}^{2}\right)\end{array}$ & $1.75 \pm 0.24$ & $1.82 \pm 0.24$ \\
\hline
\end{tabular}

Table 6. Semi-quantitative amount of 18-MEA measured by TOF-SIMS and contact angles of hair.

\begin{tabular}{cccc}
\hline Amount of 18-MEA and Contact Angles & Untreated Hair & Hair after Removal of 18-MEA \\
\hline \multicolumn{2}{c}{ Amount of 18-MEA ${ }^{1}$} & $0.37 \pm 0.14$ & 0.00 \\
\hline \multirow{2}{*}{ Contact angles } & Advancing & $102.9^{\circ} \pm 4.8^{\circ}$ & $88.0^{\circ} \pm 4.8^{\circ}$ \\
& Receding & $60.0^{\circ} \pm 9.0^{\circ}$ & $3.2^{\circ} \pm 5.0^{\circ}$ \\
\hline
\end{tabular}

${ }^{1}$ Semi-quantitative amount of 18-MEA measured by TOF-SIMS.

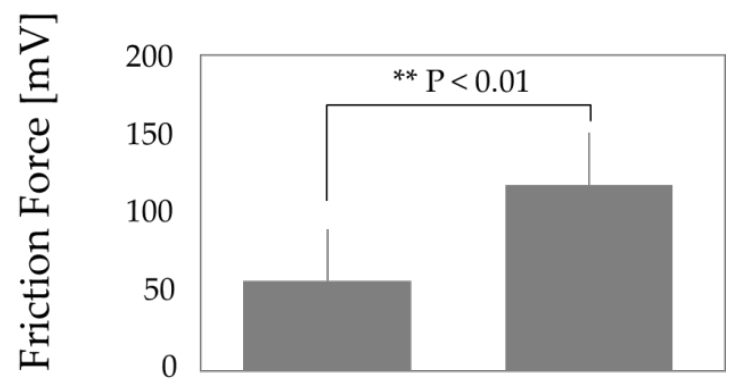

(a)

(b)

Figure 9. Friction forces of (a) untreated hair and (b) 18-MEA removed hair in wet environment $(\mathrm{n}=5)$.

Comparison of hair tresses before and after removal of 18-MEA is shown in Figure 10. There is strong difference for the shape of hair bundles after towel drying was observed. Hair fibers with 18-MEA form fine bundles with parallel hair fiber alignment. On the other hand, hair fibers without 
18-MEA form thick bundles which were disorderly. The shape of the hair bundles in a wet state influenced the appearance of hair strands after drying.

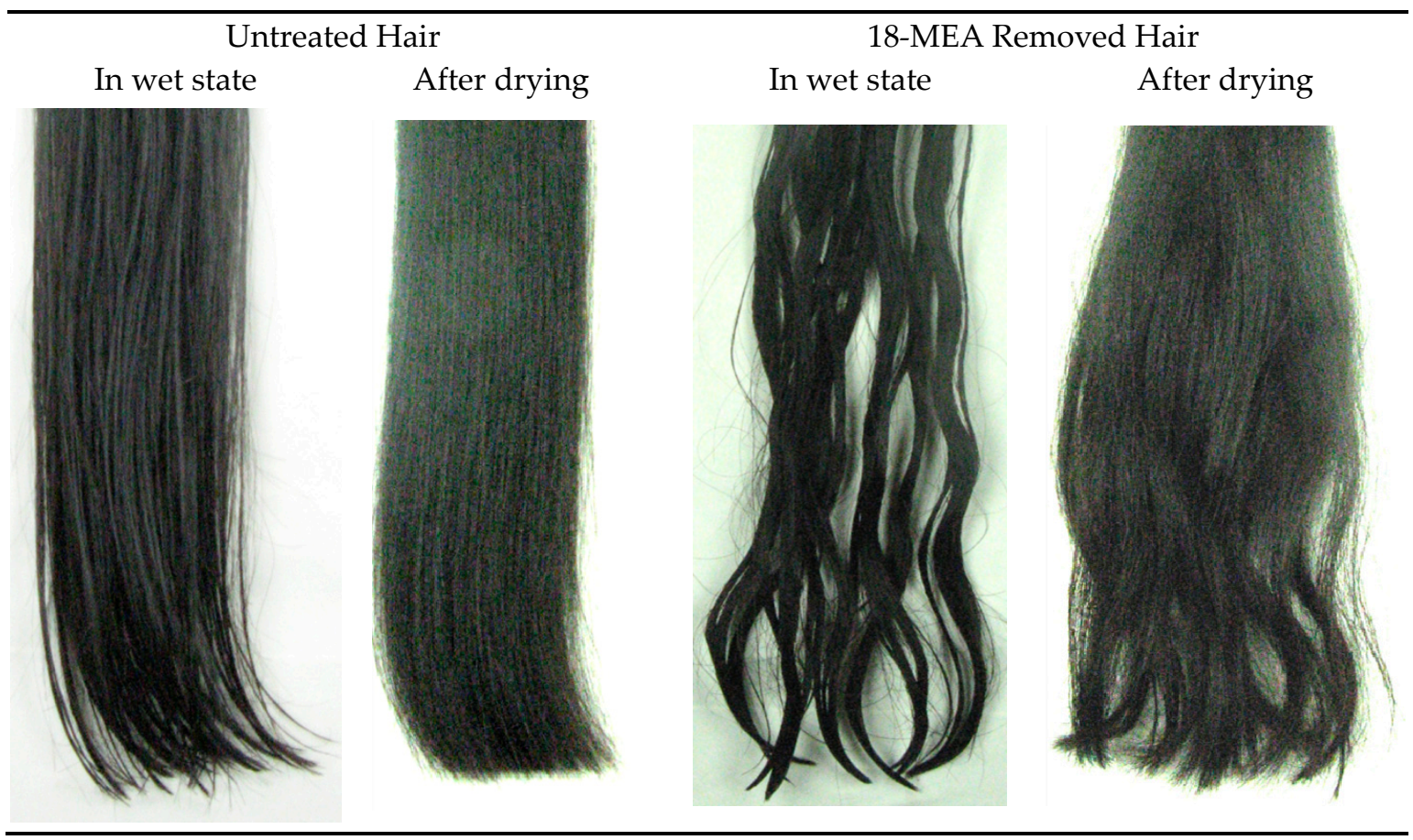

Figure 10. Shape of hair tresses in wet and dry states.

Figure 11 shows relationship between $\mathrm{q}_{\max }$ and sensory test score of moisture feeling. There is a strong relationship between sensory test score and $\mathrm{q}_{\max }$.

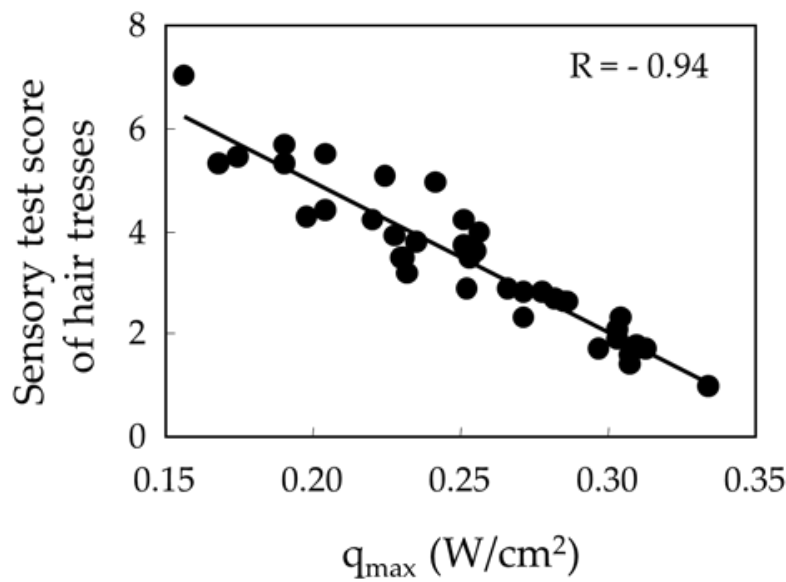

Figure 11. The relationship between the sensory test score and the $\mathrm{q}_{\max }$ of hair. The correlation coefficient $(\mathrm{R})$ was calculated by regression analysis.

Figure 12 shows relationship between the $\mathrm{q}_{\max }$ and proportion of frizzy hair to straight hair. Appearance of hair tresses made by adding curly hair fibers to straight hair tresses are also shown. This result indicates a strong relationship between $\mathrm{q}_{\max }$ and degree of order of hair alignment. 


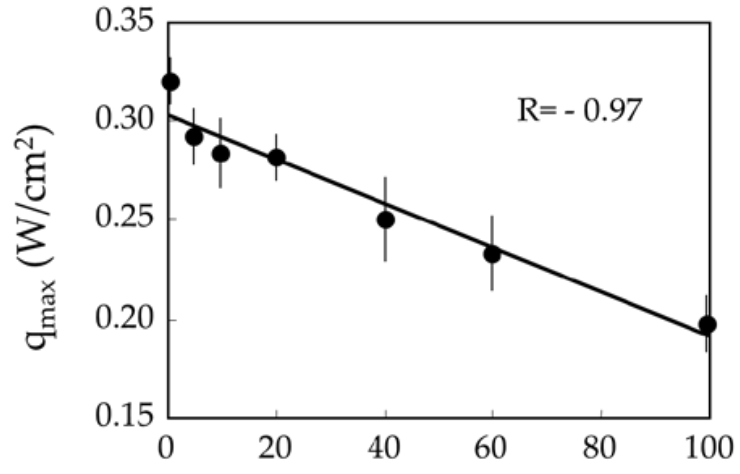

Proportion of frizzy hair to straight hair (wt $\%)$

(a)

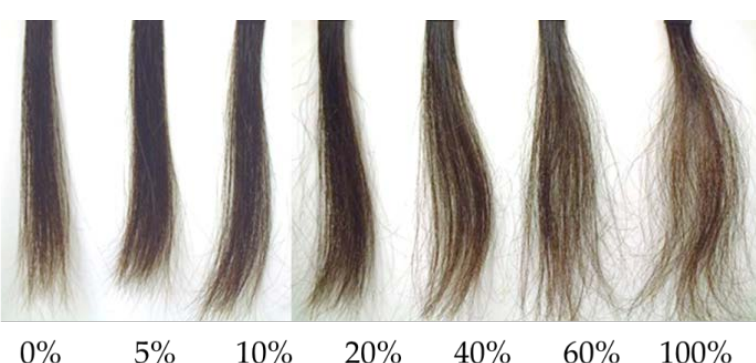

Proportion of frizzy hair to straight hair (wt\%)

(b)

Figure 12. (a) Relationship between the $q_{\max }$ and proportion of frizzy hair to straight hair in hair swatch. The correlation coefficient (R) was calculated by regression analysis. (b) Shape of hair swatches.

\section{Discussion}

\subsection{The Relationship between Surface Properties and the Amount of 18-MEA}

The semi-quantitative amount of 18-MEA on the outermost surface of hair and dynamic contact angles were measured. Advancing contact angle is the contact angle which is produced in the course of a wetting process. For the advancing contact angle, decrease happened in two distinct stages which is shown in Figure 13: firstly, when the semi-quantitative amount of 18-MEA decreased to zero, the advancing contact angle decreased gradually from $120^{\circ}$ to around $100^{\circ}$. The correlation coefficient $(R)$ was 0.76 and the p-value $(p)$ was $4.0 \times 10^{-29}(n=149)$ for the slope of the line. There was significant correlation between the advancing contact angle and the semi-quantitative amount of 18-MEA. Secondly, after the semi-quantitative amount of 18-MEA reached zero, the advancing contact angle still decreased from around $100^{\circ}$ to $70^{\circ}$. Surprisingly, some surfaces of hair did not become hydrophilic, even after losing of 18-MEA.

Receding contact angle is the contact angle which is produced in the course of a drying process. The receding contact angle decreased in a linear manner from $80^{\circ}$ to $0^{\circ}$ as the semi-quantitative amount of 18-MEA decreased to zero. The correlation coefficient (R) was 0.92 and p-value (p) was $4.0 \times 10^{-99}$ $(n=237)$ for the slope of the regression. There was significant correlation between the receding contact angle and the semi-quantitative amount of 18-MEA. The two stages of change for the decrease in advance contact angle were observed in all ethnic groups. The relationship between surface properties and the amount of 18-MEA indicates that a decrease in 18-MEA on the cuticle surface has a stronger affect on the fibers when changing from a wet to a dry environment, compared to changing from a dry to wet environment. This result corresponds to the article which indicates that the receding contact angle is more sensitive to coverage by a hydrophobic region if its coverage is high [27]. 


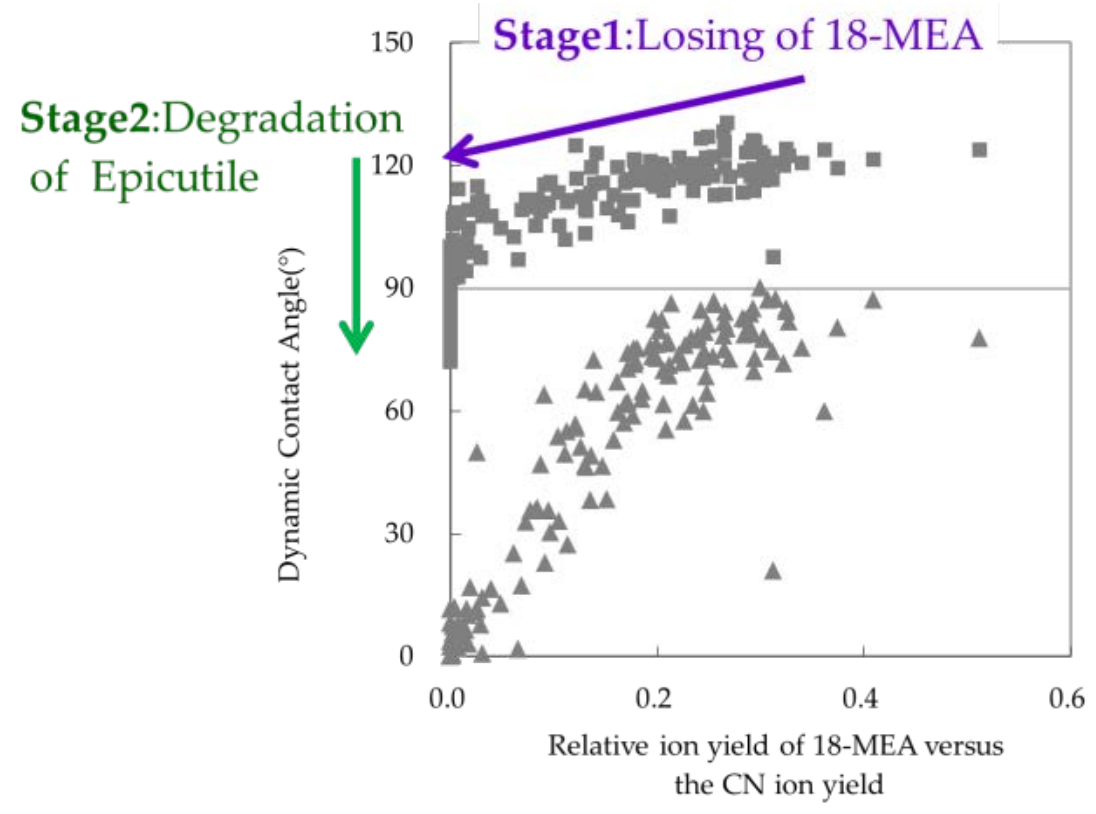

Figure 13. Explanation of two stages in hair surface degradation.

\subsection{Contribution of Epicuticle to the Hair Surface Properties}

The results (Figures 1 and 2) also indicate that some of the sampled hair fibers keep their hydrophobicity even in the absence of 18-MEA. Epicuticle whose outer layer is covered by fatty acid layer mainly consists of 18-MEA has been focused. The epicuticle was firstly reported as a thin membrane called Allwörden sac [28]. Several studies such as component analysis [29], microscopic observations [30], AFM analysis [31], and TOF-SIMS [32] have been conducted to reveal its structure; however, there is still no literature which indicates contribution of epicuticle to the hydrophobic nature of hair fiber.

Since 18-MEA binds covalently to the epicuticle via thioester or ester linkage, cleavage of these linkages by alkaline treatment produces cysteic acid [33]. Semi-quantitative analysis of sulfonate group was carried out by TOF-SIMS and X-ray photoelectron spectroscopy (XPS) measurements. In the case of XPS, atomic concentration of S(IV), which is proportional to the amount of sulfonate group [33], was measured.

As the result, B4 hair samples had a higher amount of sulfonate groups compared to B4W hair samples it showed stronger hydrophobicity than B4W hair samples. One possible interpretation of this phenomena was derived from the data of contact angle hysteresis. Hysteresis of untreated hair and $\mathrm{B} 4$ hair is almost the same at around $52^{\circ}$, whereas that of $\mathrm{B} 4 \mathrm{~W}$ hair is around $70^{\circ}$. The difference in contact angle hysteresis is explained by the mobility of hydrophilic groups [34]. Hydrophilic groups on the B4W hair are thought to be more flexible than those of untreated and B4 hair.

As previously described, the hair surface maintains its hydrophobicity only after repeatedly bleaching. Decreases in the contact angle caused by chemical treatment and mechanical damage have been described previously [35]. Our results are different from previous publications, since both the kinds of chemical treatment and the hair sampling area differ. In our study, the hair sample was cut at the root end, expecting the surface structure to be intact.

To obtain further information to indicate flexibility of hydrophilic groups of B4W hair, the elastic modulus of the epicuticle in a wet environment was measured. Epicuticle is a highly cross-linked protein layer [31]. It is expected that crosslinking density would decrease with its degradation because of mechanical degradation of the protein chain [36]. A lower crosslinking density causes easier swelling when wetted. The results indicate that only chemical treatment, that is, bleaching lotion, has no influence on the elastic modulus of the epicuticle, but the combination of chemical treatment and weathering, such as repeatedly shampooing, degrades the epicuticle. Mechanical degradation of the 
protein chain decreases crosslinking density and causes flowing out of protein fragments, believed to be the reason for the decreasing amount of sulfonate groups in B4W hair. To illustrate these findings, a schematic illustration of the epicuticle's degradation process is shown in Figure 14. After bleaching, most of the 18-MEA was removed, resulting in sulfonate groups. Sulfonate groups were fixed tightly inside the highly cross-linked protein layer reducing their contribution to hydrophobicity due to their low mobility. Treatment with both bleaching lotion and weathering, such as repeatedly shampooing, reduces crosslinking density of epicuticle because of mechanical degradation [36]. This makes the hydrophilic function groups flexible, greatly contributing to the hydrophobicity of the hair surface despite an overall decrease of sulfonate groups. [37].

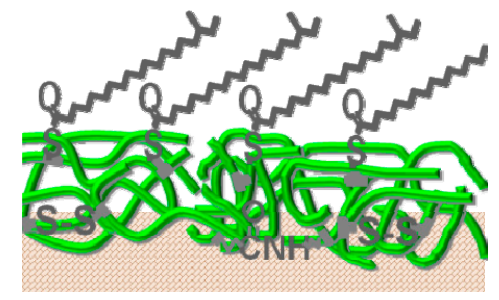

(a)

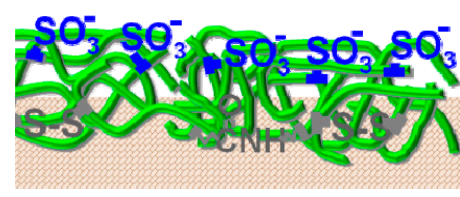

(b)

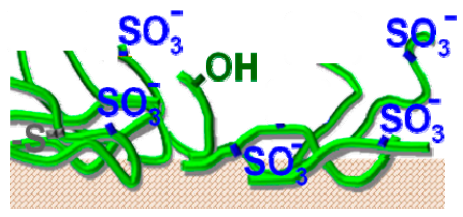

(c)

Figure 14. Schematic illustration of epicuticle's degradation process. (a) Untreated Hair (Root part). (b) B4 hair which represents chemically damaged hair. (c) B4W hair which represents chemically damaged and weathered hair.

\subsection{Regeneration of Hydrophobic Layer onto Hair Surface Using 18-MEA}

Surface properties such as contact angle and friction were recovered to the level of healthy hair by application of 18-MEA/SPDA containing conditioner and shampooed. One of the reasons why 18-MEA/SPDA shows persistent hydrophobicity was shown by AFM measurement on adsorption layer on mica, which is a model of damaged hair surface. To get a height image of the adsorption layer, mica, whose surface is atomically flat, has been used. 18-MEA/SPDA adsorption layer not only covered mica uniformly but also showed wear resistance, believed to contribute to persistent hydrophobicity.

The role of the anteiso-branch of 18-MEA has been studied [38] in order to clarify why 18-MEA/SPDA adsorption layer shows wear resistance. It is well known that the melting point of 18-MEA is approximately $20^{\circ} \mathrm{C}$ lower than that of other isomers [39]. In addition, because of the large segmental volume of the anteiso-branch structure, it was expected that the absorption layer consisting of 18-MEA will exhibit liquid-like behavior at the terminal end of the alkyl chain compare to solid-like behavior for straight chain fatty acids [4,40]. Existence of liquid-like phase on the upper side of 18-MEA/SPDA adsorption layer was demonstrated by using AFM equipped with a temperature control cell.

The layer thickness of 18-MEA/SPDA drastically increased at a temperature around $0 \sim 10{ }^{\circ} \mathrm{C}$, which was considered to be chiefly due to the anteiso-branch chain coagulation. Layer thickness of 18-MEA/SPDA was observed lower than that of n-HEA/SPDA because of the anteiso-branch chain rotation above $5^{\circ} \mathrm{C}$.

To illustrate the 18-MEA/SPDA layer, it is important to identify the molecular orientation of 18-MEA and SPDA. Results shown by ARXPS suggest that hydrophobic function groups attach to the solid surface. To comprehend the detailed structure of the stronger adsorption layer, Figure 15 shows a schematic diagram of the adsorption layer made of 18-MEA/SPDA. In this diagram, there is liquid-like phase on the upper side which is thought to contribute the wear resistance [38]. 


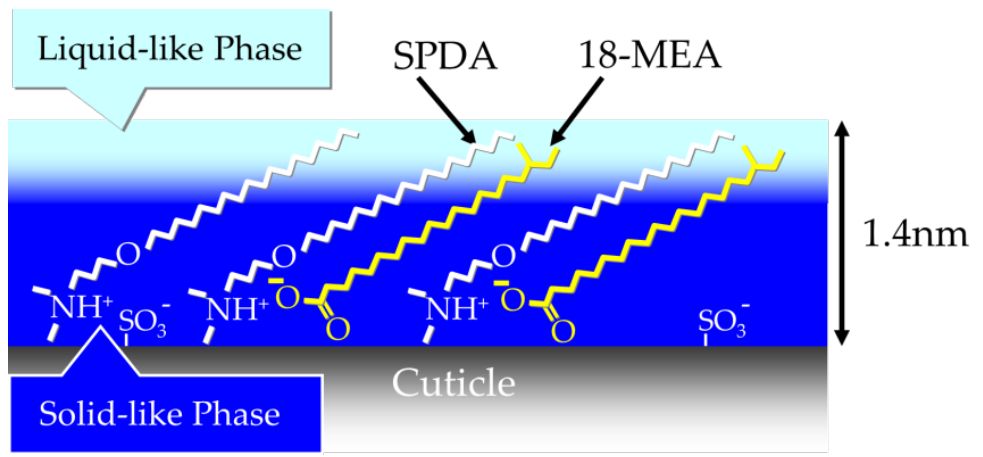

Figure 15. Schematic diagram of adsorption layer made of 18-MEA/SPDA at room temperature.

\subsection{Influences of 18-MEA on Hair Appearance and Sensory Perception}

One of the functions of 18-MEA on the surface of mammalian hair is to create a water repellency for maintenance of body temperature. In addition, influence on hair appearance [18] and sensory perception [22] via hair alignment were studied.

Structural and physical properties of hair before and after removing 18-MEA showed increases in surface friction and decreases in hydrophobicity. Strong difference for the shape of hair bundles in a wet state was observed before and after removal of 18-MEA. To avoid damage on hair internal structure such as cortex, anhydrous alkaline treatment has been used to remove 18-MEA from surface of hair fibers [41].

Figure 16 shows a schematic diagram of hair interaction in a wet state. In the case of hair fibers without 18-MEA, water between hair fibers spreads easily and causes hair fibers to bind together tightly, resulting in many tangles within the hair bundles. On the other hand, hair fibers with 18-MEA, water between hair fibers doesn't spread. Therefore, hair fibers bind together less tightly. Because of low friction, hair fibers can move easily, rearrange themselves, and finally lie in ordered parallel lines.

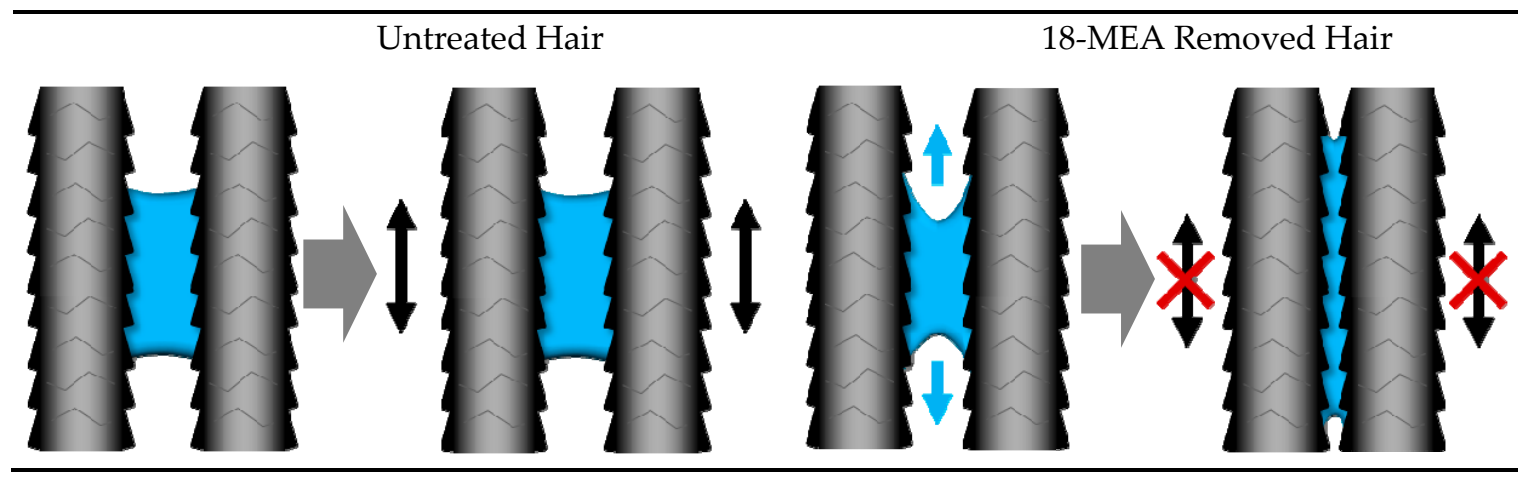

Figure 16. Schematic diagram of interactions between hair fibers in wet environment.

The relationship between hair alignment and sensory perception, such as a moisturized or dried-out feeling, was studied [22]. As previously described, the existence of 18-MEA influenced hair appearance via formation of hair alignment. A moisturized or dried-out feeling perceived was explained by heat transfer characteristic, which was closely related to degree of order of hair alignment.

A schematic diagram how 18-MEA affects hair appearance is illustrated in Figure 17. Existence of 18-MEA affects surface properties such as contact angle. Surface properties affect the shape of hair bundles in wet conditions via interaction between hair fibers. Shape of hair bundles affects hair appearance and sensory perception of hair. 


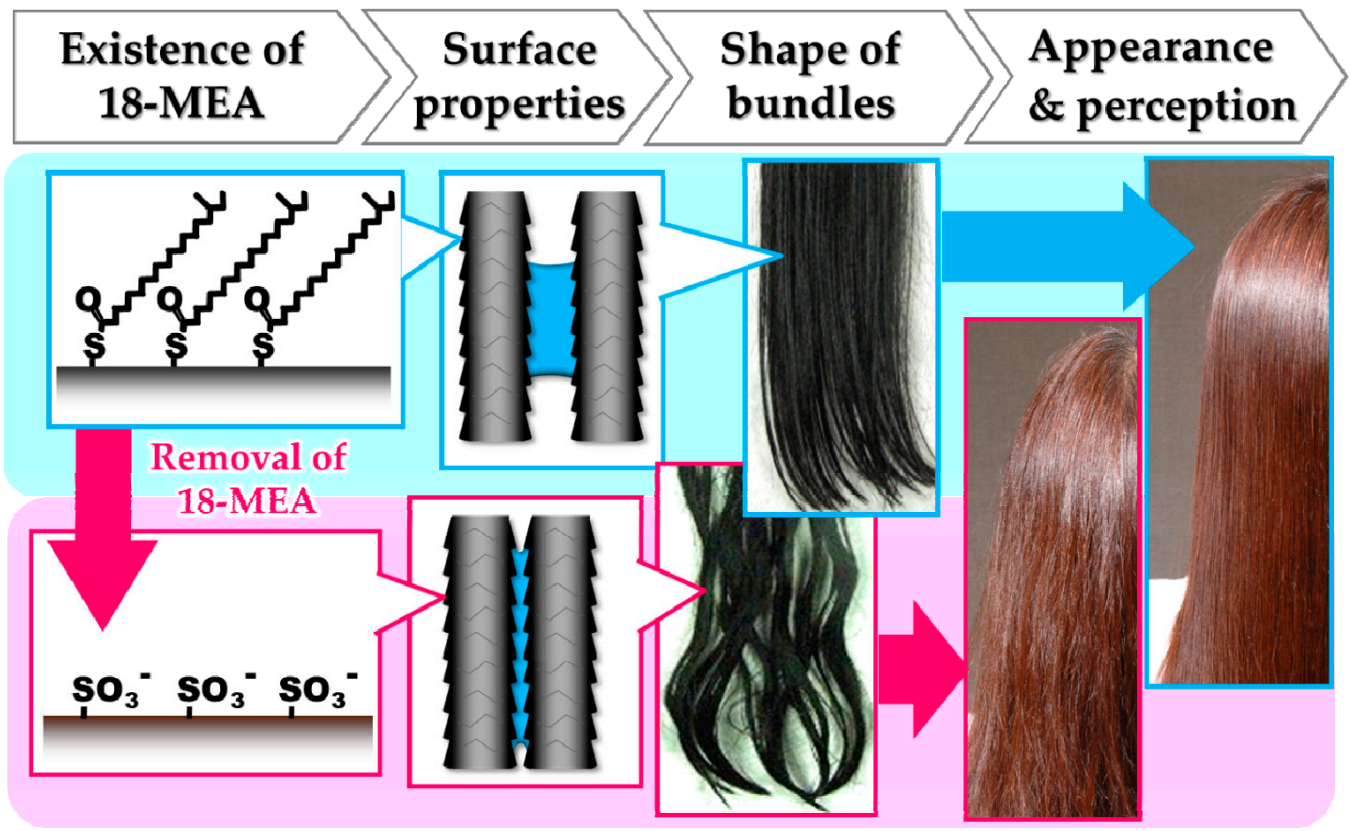

Figure 17. Schematic illustration how 18-MEA affects hair appearance and sensory pserception.

\section{Conclusions}

Surface degradation of hair was reviewed. Surface properties such as hydrophobicity and surface friction changed as surface structures of the hair fiber, that is, 18-MEA and epicuticle, degraded. Comparison of contact angle and amount of 18-MEA from root to tip of sampled hair fibers clarified contribution of not only 18-MEA but also epicuticle to the surface properties. This tendency was found for all ethnicities studied. It was found that chemical treatment by itself, such as bleaching, was not enough to cause a complete loss of hydrophobic nature, even after 18-MEA was removed. An additional weathering process, such as repeatedly shampooing, was required for complete hydrophobicity loss. After degradation of epicuticle, the hair surface turned hydrophilic. Degradation of epicuticle was accompanied by increased hysteresis of the dynamic contact angle and a decrease in elasticity in a wet state, implying cleavage of crosslinking structures.

Recovery of surface properties by using 18-MEA was also presented. 18-MEA salt with SPDA was effective for formation of a persistent adsorption layer. One of the reasons for persistency was based on liquid-like behavior around the terminal of the alkyl-chain due to rotation movement of the anteiso-branch.

Contribution to the hair beauty and sensory perception as one of the practical functions of the hair surface was studied. The hydrophobic nature of the hair surface reduced surface friction in a wet state, which reduces hair disorder alignment. Reduction of hair disorder alignment contributed to a moist feeling of hair.

\section{Patents}

1. Kao Corporation. Hair cleansing composition. JP-Patent 4745914, 9 August 2006.

2. Kao Corporation. Aqueous hair cosmetic composition. JP-Patent 4559392, CN-Patent 101321512, 9 August 2006.

3. Kao Corporation. Hair cosmetic composition. JP-Patent 4469874, 4469875, CN-Patent 101313884, US-Patent 8252272, 31 May 2007.

4. Kao Corporation. Hair cosmetic composition. JP-Patent 5094216, 11 December 2008.

Author Contributions: Conceptualization, H.T. and S.T.; investigation, S.T., H.T. and K.I; writing-review and editing, S.T and K.I. 
Funding: This research received no external funding.

Conflicts of Interest: The authors declare no conflicts of interest.

\section{Abbreviations}

$\begin{array}{ll}\text { 18-MEA } & \text { 18-methyl eicosanoic acid } \\ \text { XPS } & \text { X-ray photoelectron spectroscopy } \\ \text { SPDA } & \text { Stearoxypropyldimethylamine } \\ \text { DAPS } & \text { Dimethylaminopropylstearamide } \\ \text { STAC } & \text { Stearyltrimethylammonium chrolide } \\ \text { n-HEA } & \text { n-Heneicosanoic acid }\end{array}$

\section{References}

1. Evans, D.J.; Leeder, J.D.; Rippon, J.A.; Rivett, D.E. Separation and analysis of the surface lipids of the wool fiber. In Proceedings of the 7th International Wool Textile Research Conference I, Tokyo, Japan, 28 August-3 September 1985; pp. 135-142.

2. Wertz, P.W.; Dowing, D.T. Integral lipids of human hair. Lipids 1988, 23, 878-881. [CrossRef]

3. Wertz, P.W.; Dowing, D.T. Integral lipids of mammalian hair. Comp. Biochem. Physiol. 1989, 92B, 759-761. [CrossRef]

4. Jones, L.N.; Rivett, D.E. The role of 18-methyleicosanoic acid in the structure and formation of mammalian hair fibres. Micron 1997, 28, 469-485. [CrossRef]

5. Negri, A.P.; Cornell, H.J.; Rivett, D.E. The nature of covalently bound fatty acids in wool fibers. Aust. J. Agric. Res. 1991, 42, 1285-1292. [CrossRef]

6. Negri, A.P.; Cornell, H.J.; Rivett, D.E. Effects of proceeding on the bound and free fatty acid levels in wool. Text. Res. J. 1992, 62, 381-387. [CrossRef]

7. Evans, D.J.; Lanczki, M. Cleaavage of integral surface lipids of wool by aminolysis. Text. Res. J. 1997, 67, 435-444. [CrossRef]

8. Naito, S.; Ooshika, M.; Yorimoto, N.; Kuroda, Y. The structure of bound lipids of human hair fibers and its physical properties. In Proceedings of the 9th International Wool Textile Research Conference II, Biella, Italy, 28 June-5 July 1996; pp. 367-374.

9. Kalkbrenner, U.; Koener, H.; Hoecker, H.; Rivett, D.E. Studies on the composition of the wool cuticle. In Proceedings of the 8th International Wool Textile Research Conference I, Christchurch, New Zealand, 7-14 February 1990; pp. 398-407.

10. Carr, C.M.; Leaver, I.H.; Hughes, A.E. X-ray photoelectron spectroscopic study of the wool fiber surface. Text. Res. J. 1986, 56, 457-461. [CrossRef]

11. Breakspear, S.; Smith, J.R.; Luengo, G. Effect of the covalently linked fatty acid 18-MEA on the nanotribology of hair's outermost surface. J. Struct. Biol. 2005, 149, 235-242. [CrossRef] [PubMed]

12. Torre, C.A.; Bhusham, B.; Yang, J.-Z.; Torgerson, P.M. Nanotribological effects of silicone type, silicone deposition level, and surfactant type on human hair using atomic force microscopy. J. Cosmet. Sci. 2006, 57, 37-56. [PubMed]

13. Yasuda, M. Hand combing sensation and stiffness of hair, and science of hair surface. J. Hair Sci. 2004, 95, 7-12.

14. Tate, M.L.; Kamath, Y.K.; Ruetsch, S.B.; Weigmann, H.-D. Quantification and prevention of hair damage. J. Sci. Cosmet. Chem. 1993, 44, 347-371.

15. Tanamachi, H.; Inoue, S.; Tanji, N.; Tsujimura, H.; Oguri, M.; Ishita, M.; Tokunaga, S.; Sazanami, F. Deposition of 18-MEA onto alkaline-color-treated weathered hair to form a persistent hydrophobicity. J. Cosmet. Sci. 2009, 60, 31-44. [CrossRef]

16. Kao Corporation. Hair cosmetic Composition. JP-Patent 6053650, EP-Patent 0483689, 2 November 1990.

17. Kao Corporation. Process for Production of Ether Amine. JP-Patent 4676666, EP-Patent 1219597, US-Patent 6576794, 17 December 2001.

18. Tanamachi, H.; Tokunaga, S.; Tanji, N.; Oguri, M.; Inoue, S. 18-MEA and hair appearance. J. Cosmet. Sci. 2010, 61, 147-160. [PubMed] 
19. Ward, R.J.; Willis, H.A.; George, G.A.; Guise, G.B.; Denning, R.J.; Evans, D.J.; Short, R.D. Surface Analysis of Wool by X-Ray Photoelectron Spectroscopy and Static Secondary Ion Mass Spectrometry. Text. Res. J. 1993, 63, 362-368. [CrossRef]

20. Wortmann, F.J.; Wortmann, G.; Wiesche, S.E. Spatial Probing of the Properties of the Human Hair Surface Using Wilhelmy Force Profiles. Langmuir 2010, 26, 7365-7369. [CrossRef] [PubMed]

21. Wiesche, E.S.; Körner, A.; Schäfer, K.; Wortmann, F.J. Prevention of hair surface aging. J. Cosmet. Sci. 2011, 62, 237-249.

22. Tanamachi, H. Temperature as a moisture cue in haptics on hair. Int. J. Cosmet. Sci. 2011, 33, 25-36. [CrossRef] [PubMed]

23. Ton-That, C.; Shard, A.G.; Bradley, R.H. Thickness of spin-cast polymer thin films determined by angle-resolved XPS and AFM tip-scratch methods. Langmuir 2000, 16, 2281-2284. [CrossRef]

24. Devecchio, D.; Schmutz, P.; Frankel, G. A new approach for the study of chemical mechanical polishing. Electrochem. Solid State Lett. 2000, 3, 90-92. [CrossRef]

25. Schmutz, P.; Frankel, G.S. Influence of dichromate ions on corrosion of pure aluminum and AA2024-T3 in $\mathrm{NaCl}$ solution studied by AFM scratching. J. Electronchem. Soc. 1999, 146, 4461-4472. [CrossRef]

26. Leblanc, P.; Frankel, G.S. A study of corrosion and pitting initiation of AA2024-T3 using atomic force microscopy. J. Electronchem. Soc. 2002, 149, B239-B247. [CrossRef]

27. Robert, H.D.; Johnson, R.E., Jr. Contact Angle Hysteresis. IV. Contact Angle Measurements on Heterogeneous Surfaces. J. Phys. Chem. 1965, 69, 1507-1515.

28. Allwörden, I.K. The nature of sheep's wool and a new research method for the chemical identification of damaged wool. Z. Angew. Chem. 1916, 29,77-78.

29. Holmes, A.W. A fatty acid/protein complex in human hair. Nature 1961, 189, 923. [CrossRef] [PubMed]

30. Swift, J.A.; Holmes, A.W. Degradation of Human Hair by Papain: Part III: Some Electron Microscope Observations. Text. Res. J. 1965, 35, 1014-1019. [CrossRef]

31. Swift, J.A.; Smith, J.R. Microscopical investigations on the epicuticle of mammalian keratin fibres. J. Microsc. 2001, 204, 203-211. [CrossRef] [PubMed]

32. Okamoto, M.; Ishikawa, K.; Tanji, N.; Aoyagi, S.; Kita, I.; Migita, C.T. Structural analysis of the outermost hair surface using TOF-SIMS with C60 depth profiling technique. e-J. Surf. Sci. Nanotechnol. 2012, 10, $234-238$. [CrossRef]

33. Okamoto, M.; Ishikawa, K.; Tanji, N.; Aoyagi, S. Investigation of the damage on the outermost hair surface using ToF-SIMS and XPS. Surf. Interface Anal. 2012, 44, 736-739. [CrossRef]

34. Karlsson, J.O.; Gatenholm, P. Surface Mobility of Grafted Hydrogels. Macromolecules 1999, 32, 7594-7598. [CrossRef]

35. Lodge, R.A.; Bhushan, B. Wetting properties of human hair by means of dynamic contact angle measurement. J. Appl. Polym. Sci. 2006, 102, 5255-5265. [CrossRef]

36. Booth, C. The mechanical degradation of polymers. Polymer 1963,4, 471-478. [CrossRef]

37. Tokunaga, S.; Tanamachi, H.; Tanji, N.; Inoue, S.; Oguri, M. 18-MEA is not the only factor contributing to the hydrophobic nature of hair surface. In Proceedings of the 3rd International Conference in Applied Hair Science, Princeton, NJ, USA, 15-16 September 2008.

38. Tanamachi, H.; Inoue, S.; Tokunaga, S.; Tsujimura, H.; Tanji, N.; Oguri, M.; Habe, T. A role of the anteiso branch of 18-MEA in 18-MEA/SPDA to form a persistent hydrophobicity to alkaline-color-treated weathered hair. J. Cosmet. Sci. 2009, 60, 509-518. [CrossRef] [PubMed]

39. Weikamp, A.W. The Acidic Constituents of Degras. A New Method of Structure Elucidation. J. Am. Chem. Soc. 1945, 67, 447-454. [CrossRef]

40. Swift, J.A. Human hair cuticle: Biologically conspired to the owner's advantage. J. Cosmet. Sci. 1999, 50, $23-47$.

41. Leeder, J.D.; Rippon, J.A. Changes Induced in the Properties of Wool by Specific Epicuticle Modification. Color. Technol. 1985, 101, 11-16. [CrossRef]

(C) 2019 by the authors. Licensee MDPI, Basel, Switzerland. This article is an open access article distributed under the terms and conditions of the Creative Commons Attribution (CC BY) license (http://creativecommons.org/licenses/by/4.0/). 